\title{
VSL\#3 probiotic upregulates intestinal mucosal alkaline sphingomyelinase and reduces inflammation
}

\author{
Isaac Soo BSc ${ }^{1}$, Karen L Madsen PhD ${ }^{1}$, Qassim Tejpar BSc ${ }^{1}$, Beate C Sydora PhD ${ }^{1}$, Richard Sherbaniuk MD \\ Benedetta Cinque PhD², Luisa Di Marzio $\mathrm{PhD}^{3}$, Maria Grazia Cifone $\mathrm{PhD}^{2}$, \\ Claudio Desimone MD PhD², Richard N Fedorak MD FRCPC ${ }^{1}$
}

I Soo, KL Madsen, Q Tejpar, et al. VSL\#3 probiotic upregulates intestinal mucosal alkaline sphingomyelinase and reduces inflammation. Can J Gastroenterol 2008;22(3):237-242.

BACKGROUND: Alkaline sphingomyelinase, an enzyme found exclusively in bile and the intestinal brush border, hydrolyzes sphingomyelin into ceramide, sphingosine and sphingosine-1-phosphate, thereby inducing epithelial apoptosis. Reduced levels of alkaline sphingomyelinase have been found in premalignant and malignant intestinal epithelia and in ulcerative colitis tissue. Probiotic bacteria can be a source of sphingomyelinase.

OBJECTIVE: To determine the effect of VSL\#3 probiotic therapy on mucosal levels of alkaline sphingomyelinase, both in a mouse model of colitis and in patients with ulcerative colitis.

METHODS: Interleukin-10 gene-deficient (IL10KO) and wild type control mice were treated with VSL $\# 3$ ( $10^{9}$ colony-forming units per day) for three weeks, after which alkaline sphingomyelinase activity was measured in ileal and colonic tissue. As well, 15 patients with ulcerative colitis were treated with VSL\#3 (900 billion bacteria two times per day for five weeks). Alkaline sphingomyelinase activity was measured through biopsies and comparison of ulcerative colitis disease activity index scores obtained before and after treatment.

RESULTS: Lowered alkaline sphingomyelinase levels were seen in the colon $(\mathrm{P}=0.02)$ and ileum $(\mathrm{P}=0.04)$ of IL10KO mice, as compared with controls. Treatment of these mice with VSL\#3 resulted in upregulation of mucosal alkaline sphingomyelinase activity in both the colon $(\mathrm{P}=0.04)$ and the ileum $(\mathrm{P}=0.01)$. VSL $\# 3$ treatment of human patients who had ulcerative colitis decreased mean $( \pm$ SEM) ulcerative colitis disease activity index scores from $5.3 \pm 1.8946$ to $0.70 \pm 0.34(\mathrm{P}=0.02)$ and increased mucosal alkaline sphingomyelinase activity.

CONCLUSION: Mucosal alkaline sphingomyelinase activity is reduced in the intestine of IL10KO mice with colitis and in humans with ulcerative colitis. VSL\#3 probiotic therapy upregulates mucosal alkaline sphingomyelinase activity.

Key Words: Alkaline sphingomyelinase; Inflammatory bowel disease; Probiotic; Ulcerative colitis; VSL\#3

\section{Le probiotique VSL\#3 assure la régularisation positive de la sphingomyélinase alcaline muqueuse intestinale et réduit l'inflammation}

HISTORIQUE : La sphingomyélinase alcaline, une enzyme contenue
exclusivement dans la bile et la bordure en brosse intestinale, hydrolyse la
sphingomyéline en céramide, en sphingosine et en sphingosine-1-phos-
phate, ce qui induit une apoptose épithéliale. On a trouvé des taux moins
élevés de sphingomyélinase alcaline dans des épithéliums intestinaux pré-
cancéreux et cancéreux et dans des tissus de colite ulcéreuse. Les bactéries
probiotiques peuvent être une source de sphingomyélinase. OBJECTIF : Déterminer l'effet de la thérapie probiotique VSL\#3 sur les taux muqueux de sphingomyélinase alcaline, à la fois dans un modèle de souris atteinte de colite et chez des patients atteints de colite ulcéreuse.

MÉTHODOLOGIE : Les auteurs ont traité des souris sans gène d'interleukine-10 (IL10KO) et des souris témoins de type sauvage au VSL\#3 ( $10^{9}$ unités formant des colonies par jour) pendant trois semaines, après lesquelles ils ont mesuré l'activité de la sphingomyélinase alcaline dans les tissus iléaux et coliques. De plus, ils ont traité 15 patients atteints de colite ulcéreuse au VSL 3 (900 milliards de bactéries deux fois par jour pendant cinq semaines). Ils ont mesuré l'activité de la sphingomyélinase alcaline au moyen de biopsies et de comparaisons entre les indices d'activité de la maladie avant et après le traitement.

RÉSULTATS : Les auteurs ont observé des taux de sphingomyélinase alcaline moins élevés dans le côlon $(\mathrm{P}=0,02)$ et l'iléon $(\mathrm{P}=0,04)$ de souris IL10KO que ceux des sujets témoins. Le traitement de ces souris au moyen du VSL\#3 a donné lieu à une régularisation positive de l'activité de la sphingomyélinase alcaline muqueuse à la fois dans le côlon $(\mathrm{P}=0,04)$ et l'iléon $(\mathrm{P}=0,01)$. Le traitement des patients humains atteints de colite ulcéreuse au VSL\#3 a réduit les indices d'activité de la colite ulcéreuse moyens \pm erreur-type de 5,3 $\pm 1,8946$ à $0,70 \pm 0,34(\mathrm{P}=0,02)$ et accru l'activité de la sphingomyélinase alcaline muqueuse.

CONCLUSION : Lactivité de la sphingomyélinase alcaline muqueuse est réduite dans l'intestin des souris IL10KO atteintes de colite et chez des humains atteints de colite ulcéreuse. La thérapie probiotique VSL\#3 assure la régularisation positive de l'activité de la sphingomyélinase alcaline muqueuse.
Sphingomyelin is hydrolyzed by sphingomyelinase, a Sphingomyelin-specific form of phospholipase C; this hydrolysis appears to be a major source of ceramide. Ceramide is a lipid-signalling molecule that activates downstream caspases, which have antiproliferative and apoptotic effects on various cell types in the human body (1). Three types of sphingomyelinase have been identified in mammals. Neutral and acidic sphingomyelinases are found in various tissues throughout the body $(2,3)$. In contrast, alkaline sphingomyelinase is found only in the intestinal tract $(4,5)$ and biliary epithelium (6). Alkaline sphingomyelinase hydrolyzes intestinal and mucosal sphingomyelin $(5,7,8)$ and through

${ }^{1}$ Division of Gastroenterology, University of Alberta, Edmonton, Alberta; ${ }^{2}$ Department of Experimental Medicine, University of L'Aquila,

L'Aquila; ${ }^{3}$ Department of Drug Science, University G D'Annunzio, Chieti, Italy;

Correspondence: Dr Richard N Fedorak, University of Alberta, Division of Gastroenterology, Zeidler Ledcor Centre, 130 University Campus,

Edmonton, Alberta T6G 2H8. Telephone 780-492-6941, fax 780-492-8121, e-mail Richard.Fedorak@ualberta.ca

Received for publication December 2, 2006. Accepted October 22, 2007 
this process, stimulates the production of ceramide, which in turn, plays a significant role in apoptosis and in the prevention of intestinal epithelial dysplasia and tumourigenesis $(9,10)$.

Numerous studies have revealed associations between decreases in alkaline sphingomyelinase levels and inflammatory, premalignant or malignant conditions of the colon. For example, chronic ulcerative colitis has been found to display a $60 \%$ decrease in alkaline sphingomyelinase in areas with histologically identified dysplasia (11). In patients with familial adenomatous polyposis, a $90 \%$ reduction in alkaline sphingomyelinase activity was seen in both familial adenomatous polyposis adenomas and in surrounding normal mucosa, compared with sphingomyelinase activity in controls (12). Finally, a 75\% decrease in enzyme activity in colorectal carcinomas has been documented, compared with enzyme activity in surrounding normal tissue (13).

Upregulation of sphingomyelinase has been the focus of several experiments. For instance, exposure of sphingomyelinase to trypsin cleaves the carboxyl-terminal, releasing alkaline sphingomyelinase from the mucosa and enhancing its activity (14). Psyllium is a water-soluble fibre that acts as a food source for colonic bacteria and functions to increase stool bulk. Results from mice fed a diet that included psyllium showed a $57 \%$ increase in alkaline sphingomyelinase activity over that of controls. The addition of psyllium to a high fat diet also partially reversed that diet's negative effect on alkaline sphingomyelinase levels. However, the mechanism by which psyllium affects alkaline sphingomyelinase levels remains unclear, although a relationship to luminal bacterial growth has been suggested (15).

Gavage of Sprague-Dawley rats with an ursodeoxycholic acid suspension resulted in a dose-dependent increase in alkaline sphingomyelinase activity, to a maximal increase of $250 \%$ (8). Ursodeoxycholate has been shown to stabilize the intestinal membrane against cytotoxic agents and enhance commensal bacterial colonization. This may explain, in part, the increase of alkaline sphingomyelinase associated with ursodeoxycholate supplementation (16).

One potential mechanism for upregulating intestinal sphingomyelinase activity would be to encourage colonization of the intestinal mucosa by bacterial organisms that produce sphingomyelinase (17). VSL\#3 (VSL3 Pharmaceuticals, Inc, USA) is a probiotic product consisting of eight different strains of bacteria (Bifidobacterium longum, Bifidobacterium infantis, Bifidobacterium breve, Lactobacillus acidophilus, Lactobacillus casei, Lactobacillus bulgaricus, Lactobacillus plantarum and Streptococcus salivarius subspecies thermophilus). It has been shown to increase the numbers of its component bacteria in the colon $(18,19)$. Streptococcus thermophilus has been shown to engage in sphingomyelinase activity (20). When administered orally in the VSL $\# 3$ compound, S thermophilus colonizes the colon of $100 \%$ of patients with inflammatory bowel disease (IBD) (21).

The objectives of the present study were to examine the levels of mucosal alkaline sphingomyelinase in both an animal model of colitis and in human ulcerative colitis, and then investigate the effects of VSL\#3 probiotic therapy on the upregulation of mucosal alkaline sphingomyelinase levels.

\section{METHODS}

Animal studies

Animals: Homozygous interleukin-10 gene-deficient (IL10KO) mice (generated on a $129 / \mathrm{SvEv}$ background) and wild-type $129 \mathrm{~Sv} / \mathrm{Ev}$ controls were housed behind a barrier under specific pathogen-free conditions. All provisions for the facility were sterilized using an autoclave. Nonautoclavable supplies were sprayed with disinfectant and introduced into the facility through a high-efficiency particulate air-filtered air lock. The facility's air was high-efficiency particulate airfiltered. The animals were housed in microisolator cages covered with tight-fitting lids that contained a spun polyester fibre filter. The animals had ad libitum access to autoclaved (sterile) $9 \%$ fat rodent blocs and sterile filtered water. The facility's sanitation was verified by the Health Sciences Laboratory Animal Services at the University of Alberta (Edmonton, Alberta). Sentinel BALB/c mice were housed in the animal room and examined for known bacterial, parasitic and viral pathogens. Bacterial cultures, parasitological examinations, serological tracking profiles and histological stains were negative for all known murine viral and bacterial pathogens, indicating an intact barrier.

Animal protocol: Mice were divided into three groups: wild type placebo-fed control mice $(n=5)$; IL10KO placebo-fed mice $(n=7)$; and IL10KO mice gavaged two times per day for three weeks with $10^{9}$ colony-forming units of VSL\#3 dissolved in saline $(n=8)$. All three groups were treated for 21 days. After 21 days, the mice were given an overdose of phenobarbitol, after which the ileum and colon were removed, opened longitudinally and rinsed with ice-cold phosphate-buffered saline. A $1 \mathrm{~cm}$ segment of ileum and a similar segment of colon were extracted for histological injury assessment (see below). Ileal and colonic mucosal scrapings were obtained using a glass slide; the scrapings were immediately placed in liquid nitrogen and transferred to $\mathrm{a}-70^{\circ} \mathrm{C}$ freezer. They were then assayed for alkaline sphingomyelinase activity using the assay procedures described below.

Animal microscopic injury score: Mice in each group (see above) were analyzed for severity of colonic inflammation. Colons were excised from sacrificed animals, and one-half of the $4 \mathrm{~cm}$ segment was fixed in $10 \%$ phosphate-buffered formalin. The samples were embedded in paraffin in toto, sectioned at $1 \mathrm{~cm}$ intervals, and stained with hematoxylin and eosin for light-microscopic examination. The slides were reviewed in a blinded fashion and were assigned a histological score for intestinal inflammation using a scheme modified from Saverymuttu et al (22). Briefly, the histological grades assigned (ranging from 0 [representing no injury] to 10 [representing maximal injury]) correspond to the numerical sum of four scoring criteria: mucosal ulceration, epithelial hyperplasia, lamina propria mononuclear infiltration and lamina propria neutrophilic infiltration.

\section{Human studies}

Human protocol: The present study was performed in June and July of 2005 and was approved by the Health Research Ethics Board at the University of Alberta. Fifteen patients with clinically, endoscopically and histologically diagnosed ulcerative colitis participated. Inclusion criteria included the following requirements: being 18 years of age or older; for female participants, having a negative pregnancy blood test for the duration of the study, as well as adhering to the requirement of not breastfeeding during the study; and having a diagnosis of active or quiescent ulcerative colitis. Before admittance into the study, written and oral informed consent were obtained from all study participants. The study was performed 
in accordance with the International Conference on Harmonisation's Good Clinical Practice Guidelines, which are based on the Declaration of Helsinki. Each subject took one sachet of VSL\#3 (containing 900 billion lyophilized bacteria) orally two times per day for five weeks. Immediately before starting the VSL\#3 treatment (day 0) and again after five weeks, before stopping the VSL\#3 treatment (day 35), subjects participated in ulcerative colitis disease activity index (UCDAI) determination (23) and mucosal biopsy sampling for alkaline sphingomyelinase activity. No change in ulcerative colitis medication or dosage was permitted during the study period.

Human disease activity index: Briefly, the UCDAI is the sum (maximum of 12 points) of the scores of four criteria (scores ranked from 0 to 3 for each criterion): stool frequency, rectal bleeding, mucosal appearance and the investigator's rating of disease activity. Disease remission is defined as two points or less. Severe disease is defined as more than nine points. All biopsies were taken in the usual fashion at $20 \mathrm{~cm}$ from the anal verge. Mucosal biopsies for alkaline sphingomyelinase determination were immediately placed in liquid nitrogen and then transferred to a $-70^{\circ} \mathrm{C}$ freezer for storage. At baseline, the subjects completed a questionnaire that included questions on sex, ethnic background, year of diagnosis, frequency of disease flare-ups, surgical history and medical treatment history. At the end of the study, subjects completed a follow-up questionnaire that reported on adverse events and the initiation of new medications or surgical procedures.

\section{Alkaline sphingomyelinase activity assay}

Alkaline sphingomyelinase activity was determined using the methods previously described by Duan et al (24), with small modifications. Twenty-five microlitre samples ( $100 \mu \mathrm{g}$ to $200 \mu \mathrm{g}$ protein) were incubated for $30 \mathrm{~min}$ at $37^{\circ} \mathrm{C}$ in a buffer solution containing $50 \mathrm{mM}$ of tris-hydrochloride, $0.15 \mathrm{M}$ of sodium

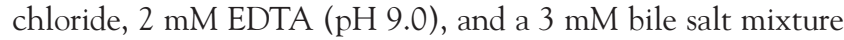
of taurocholic acid, taurodeoxycholic acid, glycocholic acid and glycochenodeoxycholic acid, with a molar ratio of 3:2:1.8:1. The reaction was started by the addition of $16 \mu \mathrm{L}$ of radiolabelled sphingomyelin ( 5 nmole) in a total volume of $200 \mu \mathrm{L}$. Briefly, 400 pmole of carbon-14-labelled sphingomyelin (specific activity $56.6 \mathrm{mCi} / \mathrm{mmol}$ [Amersham, Bucks, United Kingdom]) was mixed with 4.6 nmole of unlabelled sphingomyelin dissolved in ethanol, dried under nitrogen and added to the assay buffer. A mixed micelle solution was prepared by sonicating the tube for $1 \mathrm{~min}$. The reaction was stopped by the addition of $1 \mathrm{~mL}$ of a chloroform and methanol mixture $(2: 1$, respectively, by volume). After centrifuging, the aqueous phase was extracted twice more with chloroform. The organic phases, obtained in the different extraction steps, were collected and washed once with $1 \mathrm{~mL}$ of a chloroform, methanol and water mixture (3:48:47, respectively, by volume) to remove all of the free radioactive phosphorylcholine (the other hydrolytic product of sphingomyelin). The aqueous phases were collected and transferred to scintillation vials; the radioactive content of the vials was measured using liquid scintillation counting. The number of counts per minute represented the choline phosphate generated by sphingomyelinase hydrolysis. The percentage of hydrolysis of the substrate was calculated as the ratio of the counts of the upper phase to the total counts added into the system $(\times 100)$. The activity of sphingomyelinase was expressed as pmol sphingomyelinase hydrolyzed/h/mg tissue protein.

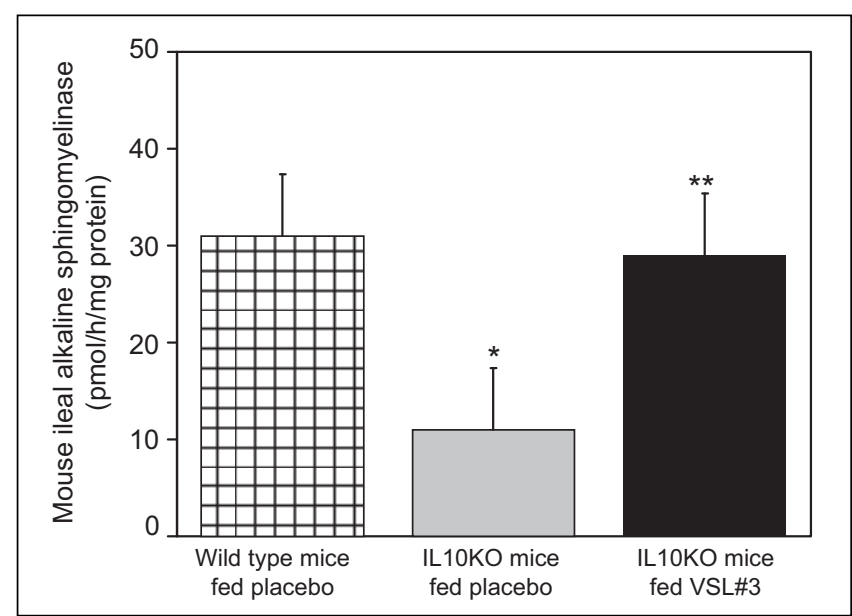

Figure 1) Mouse ileal mucosal alkaline sphingomyelinase activity. Placebo-fed interleukin-10 gene-deficient (IL10KO) mice (grey bar) demonstrated decreased ileal alkaline sphingomyelinase activity compared with placebo-fed wild type controls (hatched bar). Feeding VSL\#3 (VSL Pharmaceuticals, Inc, USA) to IL10KO mice (solid bar) returned ileal alkaline sphingomyelinase activity to control levels. Values represent mean \pm SEM for five to eight animals. $* P=0.04$ relative to placebo-fed wild type control mice; $* * P=0.01$ relative to placebo-fed IL10KO mice

\section{VSL\#3 probiotic composite}

VSL\#3 is a composite probiotic mixture containing multiple strains of three viable lyophilized bacteria species: three strains of Bifidobacterium ( $B$ longum, $B$ infantis and $B$ breve); four strains of Lactobacillus ( $L$ acidophilus, $L$ casei, $L$ bulgaricus and $L$ plantarum); and one strain of Streptococcus ( $S$ salivarius subspecies thermophilus). Each VSL\#3 sachet contained 900 billion lyophilized bacteria and contained 50.2 micro units of alkaline sphingomyelinase ( 1 micro unit of alkaline sphingomyelinase corresponds to the amount of enzyme that hydrolyzes $1 \mathrm{mmol}$ of sphingomyelin/h at $37^{\circ} \mathrm{C}$ ).

\section{Statistical analysis}

Data were analyzed using the statistical software program, Statistical Package for the Social Sciences 12.0 (SPSS Inc, USA). Unpaired T tests were performed on all comparisons of associations and of changes in enzyme activity before and after treatment. Reported P values were for two-tailed tests; $\mathrm{P}<0.05$ was considered to be significant for all statistical tests.

\section{RESULTS}

Effect of VSL\#3 supplementation on colitis and mucosal alkaline sphingomyelinase activity in IL10KO and wild type control mice

Previous studies have shown that VSL\#3 treatment normalizes the colonic epithelial barrier function and reverses histological injury; these changes correlate with a reduction in mucosal levels of proinflammatory cytokines (25). In the current study, baseline mucosal levels of alkaline sphingomyelinase activity were decreased in IL10KO mice, compared with those of wildtype control mice, in both the ileum $(\mathrm{P}=0.04$, Figure 1$)$ and the colon ( $\mathrm{P}=0.02$, Figure 2$)$. Treatment of IL $10 \mathrm{KO}$ mice with the VSL\#3 probiotic mixture significantly increased mucosal alkaline sphingomyelinase activity, compared with levels seen in placebo-fed IL1OKO mice, for both the ileum $(\mathrm{P}=0.01$, 


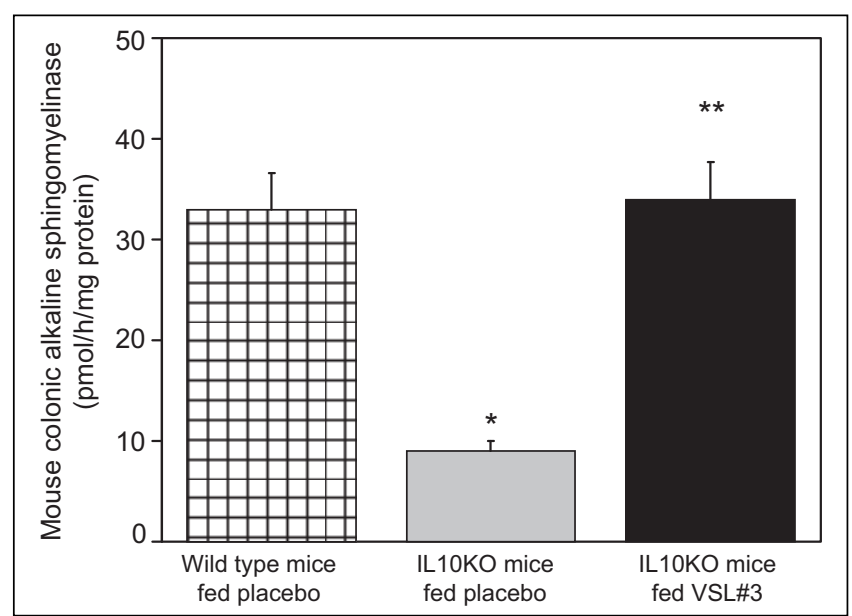

Figure 2) Mouse colonic mucosal alkaline sphingomyelinase activity. Placebo-fed interleukin-10 gene-deficient (IL10KO) mice (grey bar) demonstrated decreased colonic alkaline sphingomyelinase activity compared with placebo-fed wild type controls (hatched bar). Feeding VSL\#3 (VSL Pharmaceuticals, Inc, USA) to IL10KO mice (solid bar) returned colonic alkaline sphingomyelinase activity to control levels. Values represent mean \pm SEM for five to eight animals. $* P=0.02$ relative to placebo-fed wild type control mice; $* * P=0.04$ relative to placebo-fed IL10KO mice

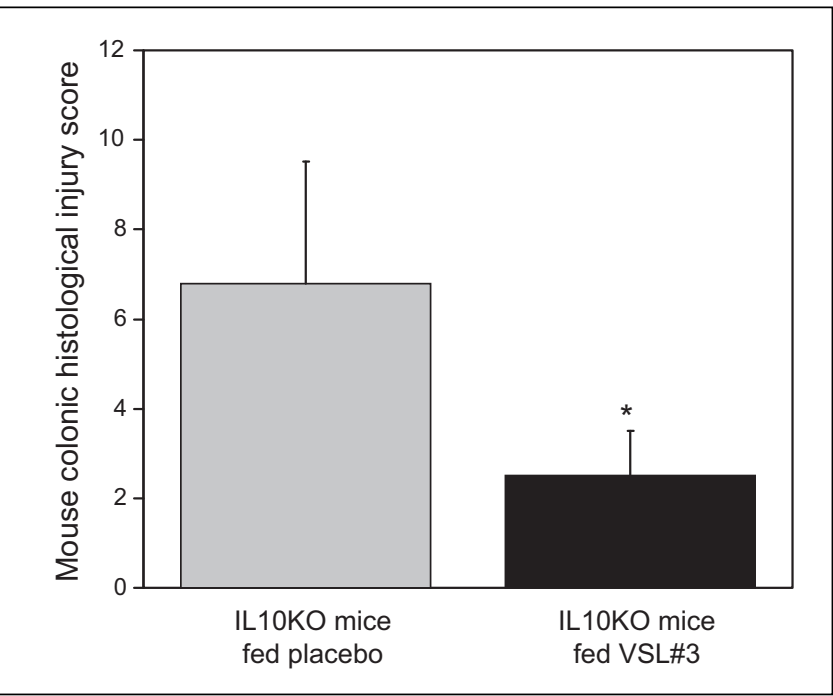

Figure 3) Mouse colonic histological injury score. Mouse histological injury score was increased in placebo-fed interleukin-10 genedeficient (IL1OKO) mice (grey bar) compared with IL10KO mice fed VSL\#3 (VSL Pharmaceuticals, Inc, USA) (solid bar). Values represent mean \pm SEM for six mice in each group. $* P=0.02$ relative to placebo-fed mice

Figure 1) and the colon ( $\mathrm{P}=0.04$, Figure 2). IL10KO mice that were not treated with VSL $\# 3$ demonstrated a mean $( \pm$ SEM) microscopic injury score of $6.7 \pm 0.6$ units; in contrast, mice treated with VSL\#3 demonstrated a marked reduction in mucosal injury, with an injury score of $2.5 \pm 0.4$ units $(\mathrm{P}=0.02)$ (Figure 3).

To confirm that the VSL\#3 itself was increasing alkaline sphingomyelinase levels, and that the increase was not simply due to improvement in inflammation, non-IBD control animals were supplemented with VSL\#3. VSL\#3 administration

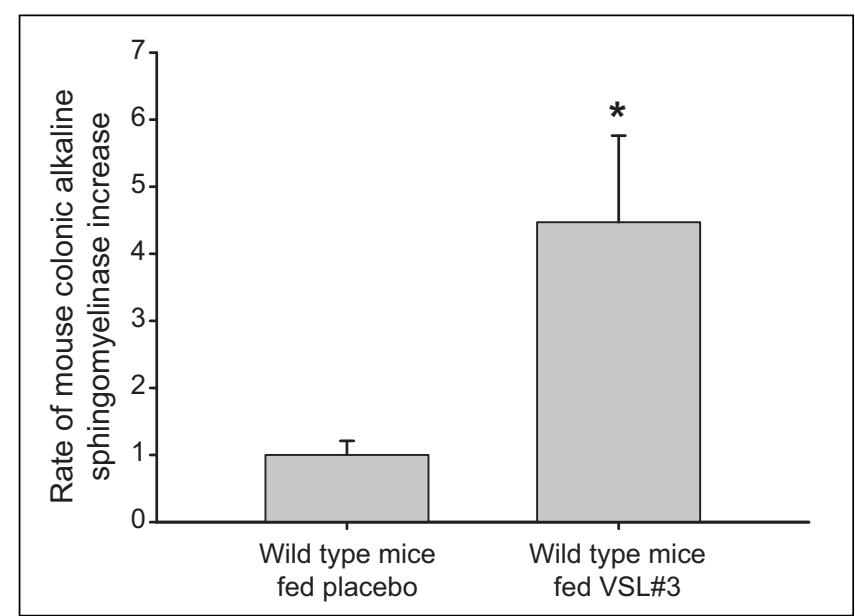

Figure 4) Mouse colonic mucosal alkaline sphingomyelinase activity. VSL\#3 (VSL Pharmaceuticals, USA)-fed wild type control mice demonstrated a fourfold increase in colonic mucosal alkaline sphingomyelinase activity compared with placebo-fed wild type controls. Values represent mean \pm SEM for six animals. $* P<0.05$ relative to placebo-fed mice

TABLE 1

Patient demographic and baseline characteristics

\begin{tabular}{lc}
\hline Variable & VSL\#3* $^{*}$ treatment group \\
\hline Men (\%):women (\%) & $9(60): 6(40)$ \\
Mean \pm SD age at entry, years & $52 \pm 12$ \\
Maximum disease extent, $\mathrm{n}(\%)$ & $6(40)$ \\
Rectum, sigmoid & $3(20)$ \\
Distal to midtransverse colon & $6(40)$ \\
Pancolitis & \\
Concomitant medications, ${ }^{\dagger}{ }^{\dagger}$ & $0(0)$ \\
Corticosteroids - oral & $3(20)$ \\
Corticosteroid - enema & $6(40)$ \\
Azathioprine or 6-mercaptopurine & $0(0)$ \\
Antibiotics & $14(93)$ \\
Mesalamine - oral & $0(0)$ \\
Mesalamine - enema & $1(7)$ \\
None &
\end{tabular}

*Manufactured by VSL Pharmaceuticals, Inc (USA); 'Medications taken within two weeks of initiating study protocol

increased mucosal alkaline sphingomyelinase levels 4.5 -fold $(\mathrm{P}<0.05)$ over those animals that were not supplemented with VSL\#3 (Figure 4). Before alkaline sphingomyelinase assessment, the VSL\#3 bacteria were removed by washing, and cultures demonstrated no residual bacteria remaining.

Effect of VSL\#3 supplementation on colitis and mucosal alkaline sphingomyelinase activity in human ulcerative colitis subjects

A total of 15 patients completed the study. The demographics of the study group are summarized in Table 1. Mean pooled data for alkaline sphingomyelinase activity demonstrate an increase in activity from $3658 \pm 1324 \mathrm{pmol}$ to $9864 \pm 1189 \mathrm{pmol}$ sphingomyelin hydrolyzed $/ \mathrm{h} / \mathrm{mg}$ protein at the end of five weeks $(\mathrm{P}<0.05$, Figure 5$)$. An overall decrease in UCDAI 


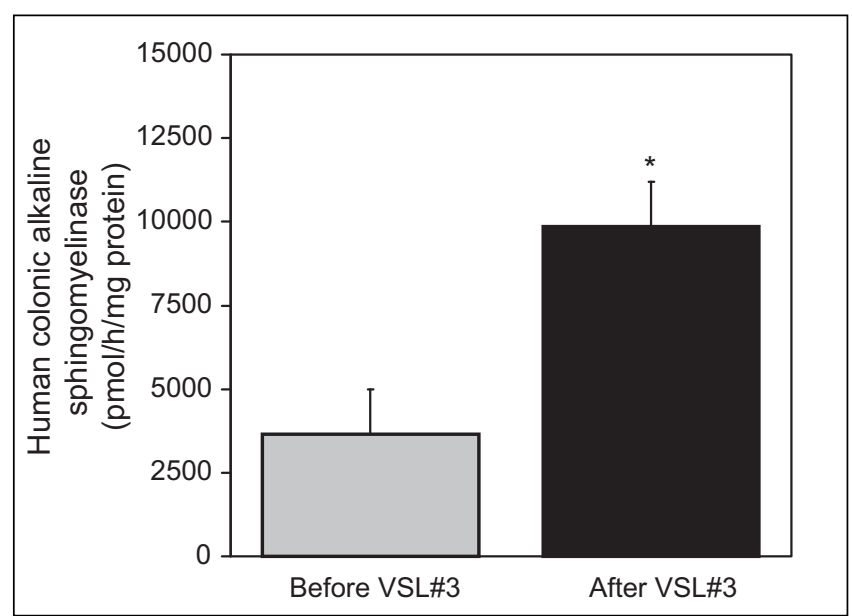

Figure 5) Human colonic mucosal alkaline sphingomyelinase activity. Feeding VSL\#3 (VSL Pharmaceuticals, Inc, USA) for five weeks to human patients with ulcerative colitis (solid bar) increased colonic mucosal alkaline sphingomyelinase activity relative to before therapy (grey bar). Values represent mean \pm SEM for 15 subjects. $* P=0.02$ relative to before VSL\#3 treatment

was evident with VSL\#3 treatment, as depicted in Figure 6 $(\mathrm{P}=0.02)$. Adverse events were minimal, with three patients reporting minor abdominal bloating.

\section{DISCUSSION}

Numerous human studies have investigated the association between inflammatory, premalignant and malignant conditions of the colon, and decreased alkaline sphingomyelinase levels (26). Studies that have investigated the upregulation of alkaline sphingomyelinase activity have focused on healthy animal models $(8,15)$. The current study, however, examined the use of VSL\#3 probiotic therapy to upregulate alkaline sphingomyelinase activity in both an animal model of colitis and humans with ulcerative colitis.

Alkaline sphingomyelinase levels in human patients with ulcerative colitis are decreased (11); our study confirms this finding and also demonstrates that IL10KO mice with colitis also demonstrate decreases in enzyme activity. Furthermore, VSL\#3 therapy upregulated both ileal and colonic mucosal levels of alkaline sphingomyelinase for these IL10KO mice to nearly normal levels. This finding was not surprising, because it was similar to results previously seen in animal models of IBD $(8,15)$. Both ileal and colonic tissues in IL10KO mice are inflamed, with evidence of elevated proinflammatory cytokines. Associated with this upregulation of alkaline sphingomyelinase by VSL \#3 administration was a statistically significant improvement in the histological injury score.

To determine whether VSL\#3 itself upregulated mucosal alkaline sphingomyelinase or whether the alkaline sphingomyelinase upregulation was due to reduced inflammation levels, VSL\#3 was administered to control (nonmucosally inflamed) animals. There was a fourfold increase in mucosal alkaline sphingomyelinase (Figure 4). Furthermore, this increase reflected pure mucosal alkaline sphingomyelinase and not residual bacterial alkaline sphingomyelinase because the VSL\#3 bacteria had, themselves, been completely washed away before the mucosal alkaline sphingomyelinase assay.

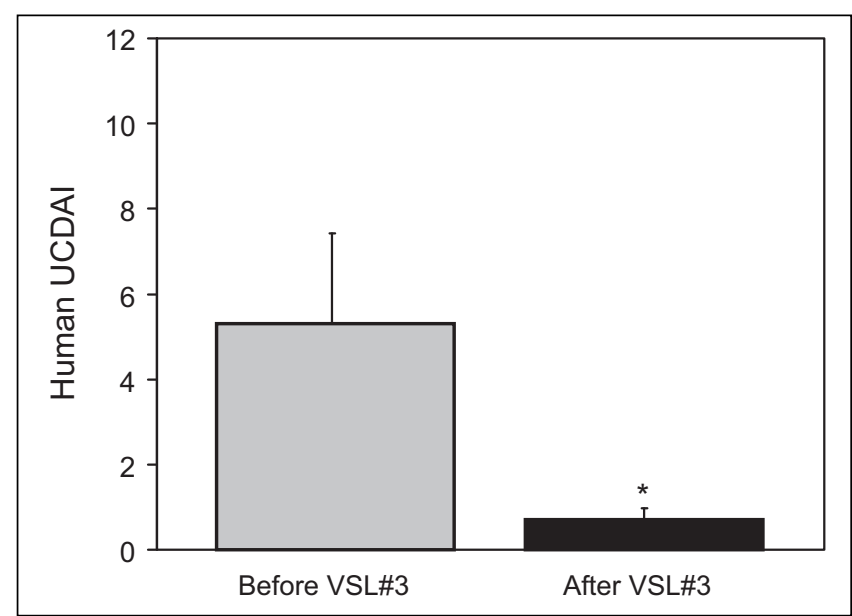

Figure 6) Ulcerative colitis disease activity index (UCDAI). The mean UCDAI score was reduced in human patients fed VSL\#3 (VSL Pharmaceuticals, Inc, USA) for five weeks (solid bar) compared with before VSL\#3 therapy (grey bar). Values represent mean \pm SEM for 15 subjects. $* P=0.02$ relative to before VSL\#3 treatment

The ability of VSL\#3 treatment to upregulate mucosal alkaline sphingomyelinase activity has potential implications for acting as an anti-inflammatory and anticarginogenic agent. Increases in alkaline sphingomyelinase have been found to correlate positively with increases in levels of caspase-3 (8), an IL1-beta-converting enzyme that has the capacity to signal apoptosis (27). In contrast, the inhibition of caspase-3 has been shown to suppress ceramide-induced apoptosis (28). Interestingly, colon cancer HT-29 cultured cells have been found to possess an inactive deletion in alkaline sphingomyelinase (9). In addition, an accumulation of sphingomyelin and a reduction in sphingomyelinase activity have been found in both human colon cancers (29) and colonic adenomatous tissue (30). The upregulation of cellular messengers, including caspase-3, may provide a possible explanation for the ability of alkaline sphingomyelinase to both induce apoptosis in adenocarcinoma cells (31) and inhibit the process of carcinogenesis (32).

In the human component of the present study, where findings were similar to those seen in the IL10KO mice with colitis, VSL\#3 administration resulted in a significant increase in mucosal alkaline sphingomyelinase activity. Sphingomyelinase activity has been described as varying in response to dietary content of fibre and fat (33), mesalamine use, changes in arachidonic acid levels $(34,35,36)$ and differences in age $(11)$. It is possible that such factors may have resulted in the increased level of sphingomyelinase observed in the human samples following VSL\#3 therapy; however, it is unlikely, because patients served as their own controls and these external variables were similar both before and during the VSL $\# 3$ treatment. Furthermore, in the animal experiments, supplementing non-IBD controls demonstrated a 4.5-fold increase in mucosal sphingomyelinase activity.

\section{CONCLUSIONS}

Mucosal alkaline sphingomyelinase activity is reduced in the intestines of IL10KO mice with colitis and humans with ulcerative colitis. Probiotic therapy with VSL\#3 upregulates alkaline sphingomyelinase activity. 


\section{REFERENCES}

1. Miyaji M, Jin ZX, Yamaoka S, et al. Role of membrane sphingomyelin and ceramide in platform formation for Fas-mediated apoptosis. J Exp Med 2005;202:249-59.

2. Ishii $\mathrm{H}$, Takahashi $\mathrm{T}$, Toyono $\mathrm{M}$, et al. Acid sphingomyelinase deficiency: Cardiac dysfunction and characteristic findings of the coronary arteries. J Inherit Metab Dis 2006;29:232-4.

3. Chatterjee S, Han H, Rollins S, Cleveland T. Molecular cloning, characterization, and expression of a novel human neutral sphingomyelinase. J Biol Chem 1999;274:37407-12.

4. Duan RD, Cheng Y, Hansen G, et al. Purification, localization, and expression of human intestinal alkaline sphingomyelinase. J Lipid Res. 2003;44:241-50.

5. Duan RD, Hertervig E, Nyberg L, et al. Distribution of alkaline sphingomyelinase activity in human beings and animals. Tissue and species differences. Dig Dis Sci 1996;41:1801-6.

6. Nyberg L, Duan RD, Alelson J, Nilsson A. Identification of an alkaline sphingomyelinase activity in human bile. Biochim Biophys Acta 1996;1300:42-8.

7. Nilsson A. Metabolism of sphingomyelin in the intestinal tract of the rat. Biochim Biophys Acta 1968;164:575-84.

8. Cheng Y, Tauschel HD, Nilsson A, Duan RD. Ursodeoxycholic acid increases the activities of alkaline sphingomyelinase and caspase- 3 in the rat colon. Scand J Gastroenterol 1999;34:915-20.

9. Wu J, Cheng Y, Nilsson A, Duan RD. Identification of one exon deletion of intestinal alkaline sphingomyelinase in colon cancer HT29 cells and a differentiation-related expression of the wild-type enzyme in Caco-2 cells. Carcinogenesis 2004;25:1327-33.

10. Hertervig E, Nilsson A, Cheng Y, Duan RD. Purified intestinal alkaline sphingomyelinase inhibits proliferation without inducing apoptosis in HT-29 colon carcinoma cells. J Cancer Res Clin Oncol 2003;129:577-82.

11. Sjoqvist U, Hertervig E, Nilsson A, et al. Chronic colitis is associated with a reduction of mucosal alkaline sphingomyelinase activity. Inflamm Bowel Dis 2002;8:258-63.

12. Hertervig E, Nilsson A, Byork J, Hultkrantz R, Duan RD. Familial adenomatous polyposis is associated with a marked decrease in alkaline sphingomyelinase activity: A key factor to the unrestrained cell proliferation? Br J Cancer 1999;81:232-6.

13. Hertervig E, Nilsson A, Nyberg L, Duan RD. Alkaline sphingomyelinase activity is decreased in human colorectal carcinoma. Cancer 1997;79:448-53.

14. Wu J, Liu F, Nilsson A, Duan RD. Pancreatic trypsin cleaves intestinal alkaline sphingomyelinase from mucosa and enhances the sphingomyelinase activity. Am J Physiol Gastrointest Liver Physiol 2004;287:G967-73.

15. Cheng Y, Ohlsson L, Duan RD. Psyllium and fat in diets differentially affect the activities and expressions of colonic sphingomyelinases and caspase in mice. Br J Nutr 2004;91:715-23.

16. Duan RD, Cheng Y, Tauschel HD, Nilsson A. Effects of ursodeoxycholate and other bile salts on levels of rat intestinal alkaline sphingomyelinase: A potential implication in tumorigenesis. Dig Dis Sci 1998;43:26-32.

17. Fuller R. Probiotics in human medicine. Gut 1991;32:439-42.

18. Brigidi P, Vitali B, Swennen E, Bazzocchi G, Matteuzzi D. Effects of probiotic administration upon the composition and enzymatic activity of human fecal microbiota in patients with irritable bowel syndrome or functional diarrhea. Res Microbiol 2001;152:735-41.

19. Brigidi P, Swennen E, Vitali B, Rossi M, Matteuzzi D. PCR detection of Bifidobacterium strains and Streptococcus thermophilus in feces of human subjects after oral bacteriotherapy and yogurt consumption. Int J Food Microbiol 2003;81:203-9.
20. Di Marzio L, Russo FP, D’Alo S, et al. Apoptotic effects of selected strains of lactic acid bacteria on a human $\mathrm{T}$ leukemia cell line are associated with bacterial arginine deiminase and/or sphingomyelinase activities. Nutr Cancer 2001;40:185-96.

21. Bibiloni R, Fedorak RN, Tannock GW, et al. VSL\#3 probioticmixture induces remission in patients with active ulcerative colitis. Am J Gastroenterol 2005;100:1539-46.

22. Saverymuttu SH, Camilleri M, Rees H, Lavender JP, Hodgson HJ, Chadwick VS. Indium 111-granulocyte scanning in the assessment of disease extent and disease activity in inflammatory bowel disease. A comparison with colonoscopy, histology, and fecal indium 111-granulocyte excretion. Gastroenterology 1986;90:1121-8.

23. Sutherland LR, Martin F, Greer S, et al. 5-Aminosalicylic acid enema in the treatment of distal ulcerative colitis, proctosigmoiditis, and proctitis. Gastroenterology 1987;92:1894-8.

24. Duan RD, Nyberg L, Nilsson A. Alkaline sphingomyelinase activity in rat gastrointestinal tract: Distribution and characteristics. Biochim Biophys Acta 1995;1259:49-55.

25. Madsen K, Cornish A, Soper P, et al. Probiotic bacteria enhance murine and human intestinal epithelial barrier function. Gastroenterology 2001;121:580-91.

26. Di Marzio L, Di Leo A, Cinque B, et al. Detection of alkaline sphingomyelinase activity in human stool: Proposed role as a new diagnostic and prognostic marker of colorectal cancer. Cancer Epidemiol Biomarkers Prev 2005;14:856-62.

27. Lazebnik YA, Kaufmann SH, Desnoyers S, Poirier GG, Earnshaw WC. Cleavage of poly(ADP-ribose) polymerase by a proteinase with properties like ICE. Nature 1994;371:346-7.

28. Yoshimura S, Banno Y, Nakashima S, et al. Ceramide formation leads to caspase-3 activation during hypoxic PC12 cell death. Inhibitory effects of Bcl-2 on ceramide formation and caspase- 3 activation. J Biol Chem 1998;273:6921-7.

29. Merchant TE, Diamantis PM, Lauwers G, et al. Characterization of malignant colon tumors with $31 \mathrm{P}$ nuclear magnetic resonance phospholipid and phosphatic metabolite profiles. Cancer 1995;76:1715-23.

30. Dudeja PK, Dahiya R, Brasitus TA. The role of sphingomyelin synthetase and sphingomyelinase in 1,2-dimethylhydrazine-induced lipid alterations of rat colonic plasma membranes. Biochim Biophys Acta 1986;863:309-12.

31. Lin CX, Umemoto A, Seraj MJ, Mimura S, Monden Y. Effect of bile acids on formation of azoxymethane-induced aberrant crypt foci in colostomized F344 rat colon. Cancer Letters, 2001;169:121-6.

32. Earnest DL, Holubec H, Wali RK, et al. Chemoprevention of azoxymethane-induced colonic carcinogenesis by supplemental dietary ursodeoxycholic acid. Cancer Res 1994;54:5071-4.

33. Yang L, Mutanen M, Cheng Y, Duan RD. Effects of fat, beef and fiber in diets on activities of sphingomyelinase, ceramidase and caspase-3 in rat colonic mucosa. Med Princ Pract 2002;11:150-6.

34. Reinacher-Schick A, Seidenstick F, Petrasch S, et al. Mesalazine changes apoptosis and proliferation in normal mucosa of patients with sporadic polyps of the large bowel. Endoscopy 2000;32:245-54.

35. Allgayer H. Review article: Mechanisms of action of mesalazine in preventing colorectal carcinoma in inflammatory bowel disease. Aliment Pharmacol Ther 2003;18(Suppl 2):10-4.

36. Reinacher-Schick A, Schoeneck A, Graeven U, Schwartz-Waldhoff I, Schmiegel W. Mesalazine causes a mitotic arrest and induces caspase-dependent apoptosis in colon carcinoma cells. Carcinogenesis 2003;24:443-51. 


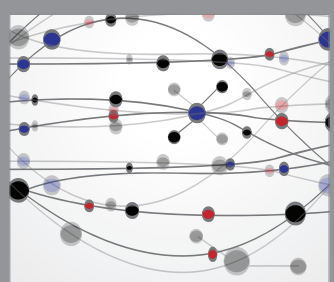

The Scientific World Journal
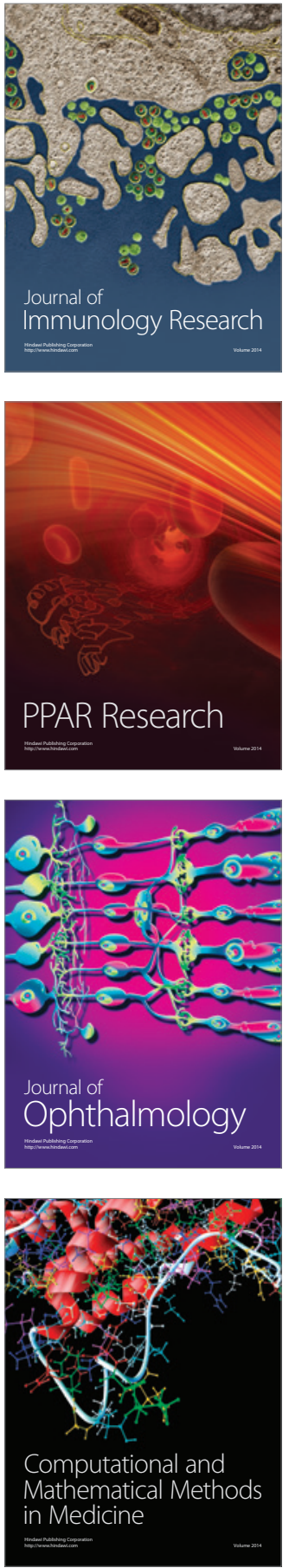

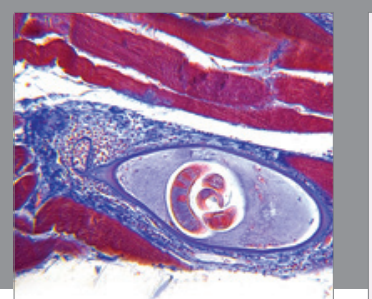

Gastroenterology Research and Practice

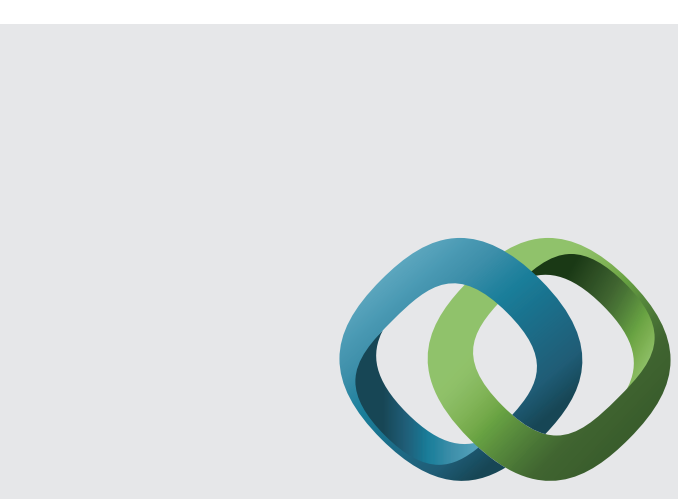

\section{Hindawi}

Submit your manuscripts at

http://www.hindawi.com
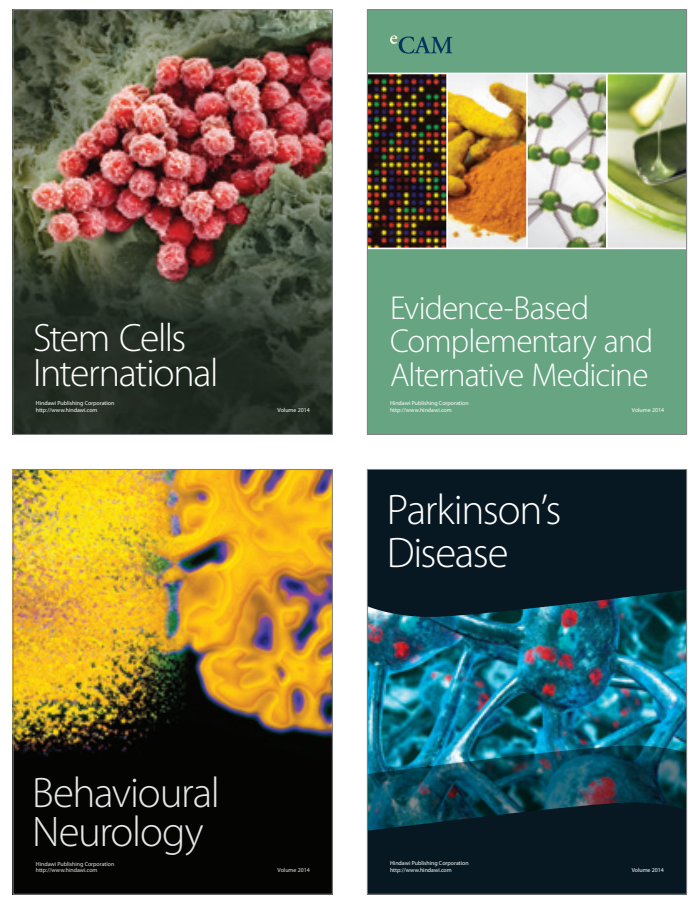
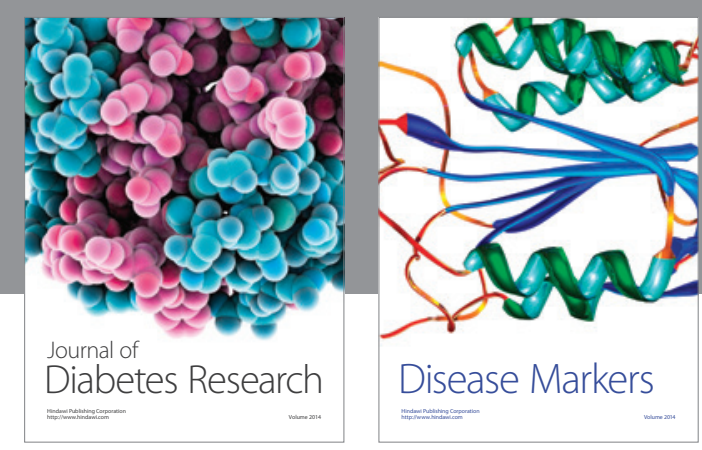

Disease Markers
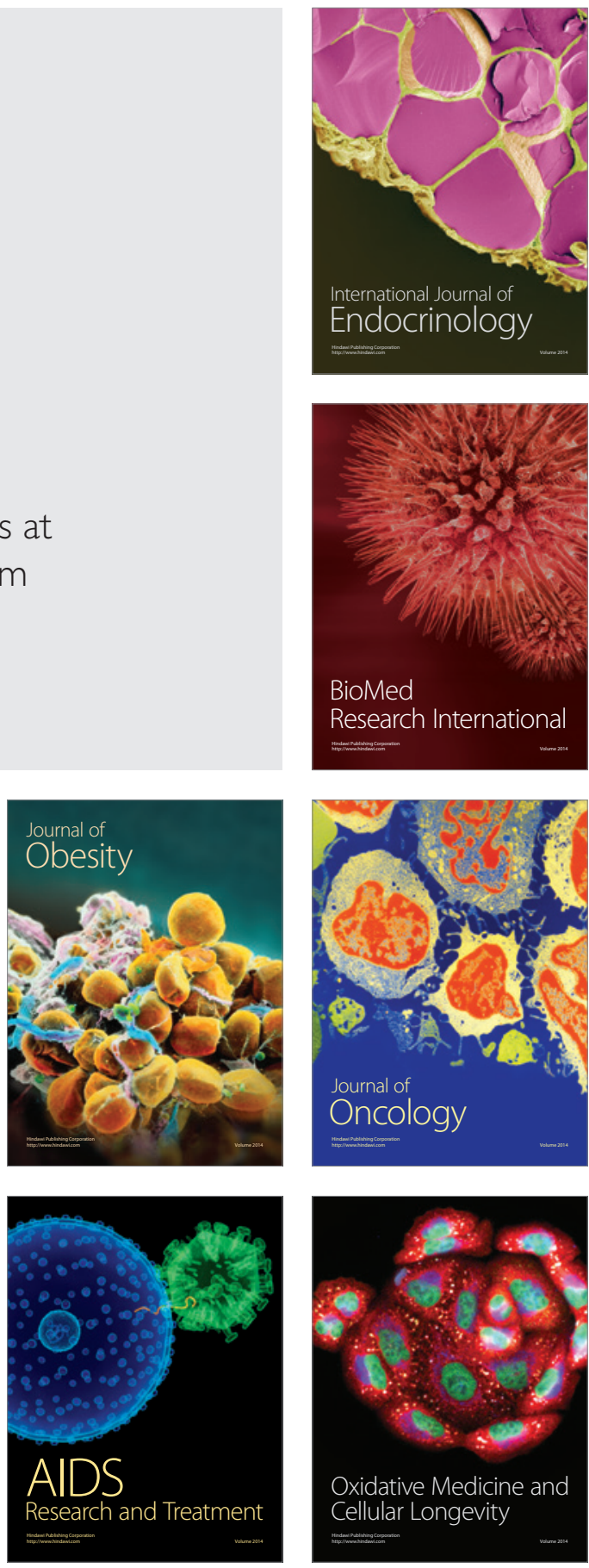